\title{
The Valuation of Multiple Stock Warrants
}

\author{
Kian-Guan Lim* $\quad$ Eric Terry ${ }^{\dagger}$
}

September 2002

*Professor of Finance, School of Business, Singapore Management University, 469 Bukit Timah Road, Singapore 259756. Email: kglim@smu.edu.sg

$\dagger$ Associate Professor, Department of Finance, Vance Academic Center \#427, 1615 Stanley Street, Central Connecticut State University, New Britain, CT 06050. The research assistance of Chang Shiwei is acknowledged. The first author is also grateful for a research grant by the Institute of High Performance Computing. 


\begin{abstract}
The issue of multiple series of stock purchase warrants by the same firm is an interesting financial structure not just in America, but is common in some countries such as Switzerland, Malaysia, and Singapore. This paper derives valuation formulas for multiple series of outstanding warrants. The theoretical warrant prices from this model are compared against existing models. We report a subtle slippage effect and also a cross dilution effect that cause the existing models such as Galai-Schneller model to be inappropriate for pricing such classes of multiple warrants. We also provide an example to illustrate the practicality of our model. The Greeks of the model are also derived in this paper. The complexity of the multiple warrants could extend to other classes of contingent securities issued by the same firm but with differing expiry terms.
\end{abstract}




\section{Introduction}

Warrants are interesting derivative securities that are often issued as sweeteners in conjunction with other debt or equity securities. Sometimes, warrants may be issued in their own right. ${ }^{1}$ Quite importantly, it is common for a firm to issue more than one series of warrants at any one time. For example, in US, NASDAQ-listed RoweCom Inc. in September 2000 issued a series of 5-year warrants together with another series of Class A 1-year warrants. NASDAQlisted Saflink Corporation in June 2000 issued simultaneously three series of Class A 12-months, Class B 18-months, and Class C 24-months warrants. Other firms, such as Digital Lava Inc., commonly had two warrant series. In Europe, Nokia, the Finnish mobile phone company, in 1995 issued bond loan with warrants permitting different warrant series. In Switzerland, warrants are commmonly issued as a means of corporate financing. In 1999, the Swiss Stock Exchange had over 1000 listed warrants from some 22 major firms. Some of these firms such as Clariant and Ciba have multiple stock warrant series. In Asia, warrants became very popular in the late 1980s and early 1990s. For example, in terms of market capitalization, warrants were the fastest growing securities in Indonesia in the mid-1990s, though they accounted for only about $0.4 \%$ of total market value. In Thailand in 1999, there were 392 warrant listings with $10.5 \%$ market capitalization. In Hong Kong in 1997, there were 156 stock warrants, 219 derivative warrants ${ }^{2}$, and 591

\footnotetext{
${ }^{1}$ For example, in 1979, Chrysler gave the federal government stock warrants in exchange for guaranteed private loans.

${ }^{2}$ In the international context, warrants go by different names in different countries. In North America, stock purchase warrants are issued by a firm against its own shares. When the warrants are exercised, the firm issues additional stock shares to the warrant holders who tender the warrants together with the exercise price payments. European countries such as U.K., and Scandinavian countries such as Finland, typically refer to these securities as warrants. In Asian countries once under the commonwealth, stock purchase warrants used to be, and are sometimes called transferable subscription rights,
} 
ordinary stocks. Market capitalization of warrants grew at a rapid rate of $26 \%$ per annum for a whole decade. Because of their popularity, it is common for Asian firms to issue two or more series of stock warrants at any one time. This is particulary evident in Malaysia, and to a lesser extent, Singapore. The Malaysian Kuala Lumpur Stock Exchange in 2000 had 809 listed stocks and over 120 listed warrants with a $1.85 \%$ market capitalization. Of the 88 listed warrants, 35 were multiple series issues from 16 different firms. In Singapore in 2001, there were 46 warrants and 312 ordinary stocks. Many firms such as DBS, SIA, Freight Links Express, Strike Engineering, and Globa, had issued multiple series of warrants.

Stock purchase warrants result in new shares being issued when they are exercised. ${ }^{3}$ The issue of new shares leads to an effect known as price dilution, which has an impact on warrant pricing. In their seminal paper, Black and Scholes (1973) suggest that their option pricing model can be used to value or TSRs in short. Examples are found in Malaysia and Singapore. In Hong Kong, firmissued warrants are called equity warrants, whereas derivative warrants are another type of warrants issued by a third party firm. This third party firm is not the same as the firm issuing the underlying ordinary shares. These latter warrants are sometimes called derivative call warrants or derivative put warrants to distinguish the availability of call and put types. In North American terminology, when issued by investment banks, the derivative warrants are called covered warrants. The issuing banks have certain obligations to cover its exposure by inventorying some amounts of the shares. In Australia, derivative warrants are common and are sometimes called equity calls. Likewise, derivative warrants are common in Taiwan, and are simply termed equity warrants. These should not be confused with the stock purchase warrants that are less common in Taiwan. Covered and derivative warrants do not result in the issue of new shares when they are exercised. Elsewhere in Asia, such as Thailand, Korea, and Indonesian, warrants simply mean stock purchase warrants. In Indonesia, there are no other forms of warrants such as derivative warrants with third party issuers.

${ }^{3}$ Another important and common type of warrants are the executive stock options that have been used extensively in optimizing executive compensation. However, unlike stock warrants, they are not traded and are nontransferable. 
stock warrants. Galai and Schneller (1978) propose an extension of the BlackScholes model that accounts for the price dilution. Under the assumption that the firm has only one series of outstanding warrants, they show that the value of each stock warrant equals the value of an equivalent call option on the firm's equity multiplied by an adjustment for dilution. The Galai and Schneller approach is distribution-free as the dilution adjustment can be applied whatever is the underlying process of the asset price. The underlying process needs not be a geometric Brownian motion as in the Black-Scholes model. However, for purpose of direct comparison with the Black-Scholes model, geometric Brownian motion is assumed to be the underlying asset price process when the Galai-Schneller approach or model is mentioned in the rest of this paper. Other alternative models have been proposed for valuing stock warrants. For example, Lauterbach and Schultz (1990) recommend the use of a dilution-adjusted version of the CEV option pricing model (Cox and Ross, 1976). These models all assume that the firm has only one series of outstanding warrants.

When a firm has two or more series of outstanding stock warrants, the exercise of one series of warrants dilutes the share price that would be received from exercising the later warrant series. This creates a cross-dilution effect that can be significant on the fair value of the later warrant series. At the same time, we isolate the reverse effect of the potential dilution of the later warrant series on the fair price of the earlier series warrants, and call this a slippage effect. In this paper, we examine warrant pricing when a firm has multiple series of outstanding stock warrants. Section 2 presents valuation formulas for the case of the firm having two warrant series outstanding simultaneously. The risk-neutral pricing method of Cox and Ross (1976) is used to derive these formulas, although alternative derivations are possible. These formulas can easily be extended to cases of three or more series of outstanding warrants. In section 3, prices from the multiple warrant model are 
compared against those predicted by the Galai-Schneller and Black-Scholes models. The results indicate that the Galai-Schneller model tends to overprice the multiple warrants due to the slippage and cross-dilution effects that are not captured in modelling with only one warrant series. Likewise, the Black-Scholes model tends to overprice both warrant series. This analysis implies that the multiple warrants model should significantly outperform other models when the potential dilution of the warrants is high, the warrants are out-of-the money, or when the terms to expiry are longer. We also provide an example to illustrate the practicality of our model. Derivations of the Greeks or hedge ratios are shown in section 4 . Finally, section 5 presents avenues for future research and concludes the paper.

\section{The Pricing Model}

Consider an all-equity firm that has $n$ common shares outstanding. In addition to its common shares, the firm has $n_{A}$ series $\mathrm{A}$ warrants that are outstanding and $n_{B}$ series $B$ warrants that are outstanding. The series A warrants mature at $T_{A}$ and have an exercise price of $K_{A}$ each, while the series B warrants mature at $T_{B}$ and have an exercise price of $K_{B}$ each. Without loss of generality, it is assumed that $T_{B}>T_{A}$, i.e., the series $\mathrm{B}$ warrants expire after the series A warrants, and that the conversion ratio for both series of warrants is one. For simplicity, suppose that the firm pays no dividends and that conditions such as in Constantinides (1984) and Spatt and Sterbenz (1988) prevent any gain from strategic sequential exercise by warrant holders, so that each series of warrants may be valued as if it will either expire without exercise or be exercised at expiry as single blocks. ${ }^{4}$ The value of the

\footnotetext{
${ }^{4}$ Emanuel (1983) shows that strategic exercise of warrants can occur when the warrants are concentrated in the hands of one investor.
} 
firm, $V$, is assumed to follow the Ito process

$$
d V=\left(\alpha d t+\sigma d Z_{t}\right) V
$$

where $\alpha$ is the instantaneous expected rate of return on the firm, $\sigma$ is the instantaneous return variance on the firm, and $d Z_{t}$ is a standard Weiner process. $V$ describes the value of the firm excluding any exercise proceeds from the warrants. Let $r$ be the continuously compounded riskless interest rate, which is assumed to be constant. Finally, suppose that the proceeds from any warrant exercise are invested in riskless assets by the firm.

Backwards recursion is used to determine the value of these warrants. First, the value of the warrants at $T_{A}$, the expiry date of the series A warrants, is computed. Since the series A warrants will have expired, the firm has only one series of warrants outstanding after $T_{A}$. These series $\mathrm{B}$ warrants can be valued using the warrant pricing formula of Galai and Schneller (1978). There are two cases to be considered. First, suppose that the series A warrants are not exercised at $T_{A}$. In this case, the value of each series $\mathrm{B}$ warrant at $T_{A}$ will be

$$
W_{B, T_{A}}^{u}=\frac{1}{n+n_{B}}\left[V_{T_{A}} N\left(d_{1}^{u}\right)-n K_{B} e^{-r\left(T_{B}-T_{A}\right)} N\left(d_{2}^{u}\right)\right]
$$

where

$$
\begin{aligned}
d_{1}^{u} & =\frac{\ln \left(V_{T_{A}} / n K_{B}\right)+\left[r+\sigma^{2} / 2\right]\left(T_{B}-T_{A}\right)}{\sigma \sqrt{T_{B}-T_{A}}}, \\
d_{2}^{u} & =d_{1}^{u}-\sigma \sqrt{T_{B}-T_{A}},
\end{aligned}
$$

and $N(d)$ represents the standard cumulative normal distribution. Since they are not exercised, the series $\mathrm{A}$ warrants will have no value at $T_{A}$ under this scenario. Alternatively, suppose that the series $A$ warrants are exercised at $T_{A}$. In this case, the value of the firm will increase by $n_{A} K_{A}$ and the number of outstanding shares will rise to $n+n_{A}$ at that time. The value of each 
series B warrant will therefore be

$W_{B, T_{A}}^{e}=\frac{1}{n+n_{A}+n_{B}}\left\{V_{T_{A}} N\left(d_{1}^{e}\right)+\left[n_{A} K_{A}-\left(n+n_{A}\right) K_{B} e^{-r\left(T_{B}-T_{A}\right)}\right] N\left(d_{2}^{e}\right)\right\}$,

where

$$
\begin{aligned}
& d_{1}^{e}=\frac{\ln \left(V_{T_{A}} /\left[\left(n+n_{A}\right) K_{B}-n_{A} K_{A} e^{r\left(T_{B}-T_{A}\right)}\right]\right)+\left[r+\sigma^{2} / 2\right]\left(T_{B}-T_{A}\right)}{\sigma \sqrt{T_{B}-T_{A}}} \\
& d_{2}^{e}=d_{1}^{e}-\sigma \sqrt{T_{B}-T_{A}} .
\end{aligned}
$$

Meanwhile, the value of each series $\mathrm{A}$ warrant at time $T_{A}$ is given by the boundary condition

$$
\begin{aligned}
W_{A, T_{A}} & =\max \left\{0, S_{T_{A}}-K_{A}\right\} \\
& =\max \left\{0, \frac{1}{n+n_{A}}\left(V_{T_{A}}+n_{A} K_{A}-n_{B} W_{B, T_{A}}^{e}\right)-K_{A}\right\},
\end{aligned}
$$

where $S_{t}$ represents the firm's share price at time $t$. This expression simplifies to

$$
W_{A, T_{A}}=\max \left\{0, \frac{1}{n+n_{A}}\left(V_{T_{A}}-n K_{A}-n_{B} W_{B, T_{A}}^{e}\right)\right\} .
$$

This formula implies that the series A warrants will be exercised at $T_{A}$ whenever the value of the firm exceeds $V^{*}$, which is given by

$$
V^{*}=n K_{A}+n_{B} W_{B, T_{A}}^{e}\left(V^{*}\right) .
$$

Here, we have shown $W_{B, T_{A}}^{e}$ as an explicit function of $V^{*}$ to emphasize the fact that this equation must be solved iteratively for $V^{*}$.

Given the prices of the two warrant series at $T_{A}$, their current value can be determined using the risk-neutral pricing method of Cox and Ross (1976). Let $F\left(V_{T_{A}} \mid V_{0}\right)$ represent the distribution of the value of the firm at $T_{A}$ conditional upon its current value. Then, the current value of each series A warrant at $t=0$ is given by

$$
W_{A, 0}=\frac{1}{n+n_{A}} e^{-r T_{A}} \int_{V^{*}}^{\infty}\left[V_{T_{A}}-n K_{A}-n_{B} W_{B, T_{A}}^{e}\right] d F\left(V_{T_{A}} \mid V_{0}\right) .
$$


Substituting for $W_{B, T_{A}}^{e}$ using equation (2) and taking the appropriate integrals, we find that

$$
\begin{aligned}
W_{A, 0}= & \frac{1}{n+n_{A}}\left\{V_{0} N\left(d_{1}^{*}\right)-n K_{A} e^{-r T_{A}} N\left(d_{2}^{*}\right)-\frac{n_{B}}{n+n_{A}+n_{B}}\right. \\
& {\left[V_{0} M\left(d_{1}^{*}, d_{1}^{\prime} ; \sqrt{T_{A} / T_{B}}\right)+\left[n_{A} K_{A} e^{-r T_{A}}-\left(n+n_{A}\right) K_{B} e^{-r T_{B}}\right]\right.} \\
& \left.\left.M\left(d_{2}^{*}, d_{2}^{\prime} ; \sqrt{T_{A} / T_{B}}\right)\right]\right\},
\end{aligned}
$$

where

$$
\begin{aligned}
d_{1}^{*} & =\frac{\ln \left(V_{0} / V^{*}\right)+\left[r+\sigma^{2} / 2\right] T_{A}}{\sigma \sqrt{T_{A}}} \\
d_{2}^{*} & =d_{1}^{*}-\sigma \sqrt{T_{A}}, \\
d_{1}^{\prime} & =\frac{\ln \left(V_{0} /\left[\left(n+n_{A}\right) K_{B}-n_{A} K_{A} e^{r\left(T_{B}-T_{A}\right)}\right]\right)+\left[r+\sigma^{2} / 2\right] T_{B}}{\sigma \sqrt{T_{B}}}, \\
d_{2}^{\prime} & =d_{1}^{\prime}-\sigma \sqrt{T_{B}},
\end{aligned}
$$

and $M(a, b ; \rho)$ represents the bivariate cumulative normal distribution with $a$ and $b$ as upper limits and $\rho$ as the correlation coefficient. Similarly, the current value of each series B warrant is

$$
\begin{aligned}
W_{B, 0}= & e^{-r T_{A}}\left[\int_{0}^{V^{*}} W_{B, T_{A}}^{u} d F\left(V_{T_{A}} \mid V_{0}\right)+\int_{V^{*}}^{\infty} W_{B, T_{A}}^{e} d F\left(V_{T_{A}} \mid V_{0}\right)\right] \\
= & \frac{1}{n+n_{B}}\left[V_{0} M\left(-d_{1}^{*}, d_{1}^{\prime \prime} ;-\sqrt{T_{A} / T_{B}}\right)-n K_{B} e^{-r T_{B}} M\left(-d_{2}^{*}, d_{2}^{\prime \prime} ;-\sqrt{T_{A} / T_{B}}\right)\right] \\
& +\frac{1}{n+n_{A}+n_{B}}\left[V_{0} M\left(d_{1}^{*}, d_{1}^{\prime} ; \sqrt{T_{A} / T_{B}}\right)+\left[n_{A} K_{A} e^{-r T_{A}}-\left(n+n_{A}\right) K_{B} e^{-r T_{B}}\right]\right. \\
& \left.M\left(d_{2}^{*}, d_{2}^{\prime} ; \sqrt{T_{A} / T_{B}}\right)\right],
\end{aligned}
$$

where

$$
\begin{aligned}
& d_{1}^{\prime \prime}=\frac{\ln \left(V_{0} / n K_{B}\right)+\left[r+\sigma^{2} / 2\right] T_{B}}{\sigma \sqrt{T_{B}}}, \\
& d_{2}^{\prime \prime}=d_{1}^{\prime \prime}-\sigma \sqrt{T_{B}},
\end{aligned}
$$


and the other cumulative normal limits are defined above.

These formulas are perhaps the first sets of theoretical results involving multiple warrants or contingent firm-based securities in the literature. In the pricing of the earlier expiry warrant series $\mathrm{A}$ in (5), the first two terms reflect the potential for payoff to exercise of series A warrants when the underlying per share firm value is sufficiently high compared to $K_{A}$. The last and remaining term represents the value of series B warrants in (2) that must be subtracted from firm value in order to arrive at series A warrant price. Another way to view a series A warrant is to likened it to a compound call option, developed by Geske (1979), where if it is exercised at $T_{A}$, the stocks are sold and exchanged into series B warrants at market price. There are two major differences, however, in trying to compare with compound options or call on call. First, there is a complicated pattern of dilutions here involving two separate warrants. These dilutions affect the equilibrium warrant prices in a complicated way. Second, it is simpler in a compound option when the payment at $T_{A}$ to hold later expiry calls is fixed ex-ante at $K_{A}$. However, in our multiple warrant case here, the payment at $T_{A}$ to hold later expiry warrants is not fixed ex-ante now, but depends on the price of series $\mathrm{B}$ warrants at time $T_{A}$. This is an important difference which makes our pricing a level more intricate, and in fact makes the compound option formulation a special case of our model when there is no dilution, and when exercise into later series derivatives can be fixed ex-ante. The latter is indeed a valuable option in itself, and ceteris paribus, would make the compound option setup more expensive than the multiple warrants setup. This explains why in (5), the third and last term actually reduce the current equilibrium price of series A warrants if the underlying firm value is high and there is high dilution.

For the price of series B warrants in (6), the last term is a simple negative multiple of the last term in (5). The current price of series A warrants is 
affected in some inverse manner with the price of later expiry series B warrants. As we saw earlier, higher underlying stock price increases moneyness of series B warrants, enhancing its exercise potential, and thus attenuates series A warrant price. This subtle attenuation effect that we call the slippage effect is not reported in any earlier literature, and is not captured in compound options literature. Unlike the cross-dilution effect that is more immediately transparent and that affects the later warrant series, the slippage effect affects the earlier warrant series. These effects are interesting and have implications on an investor who is deciding to invest in both series A and series B warrants.

Although the risk-neutral pricing method of Cox and Ross (1976) was used to arrive at the pricing formulas, other derivations are possible. For example, the payoff of each warrant series can be duplicated using a dynamic portfolio of the firm's equity and riskless bonds. The warrants can then be competitively priced against this portfolio (see Ross (1978)). Although the valuation formulas apply only to the case of two series of warrants outstanding simultaneously, the model can in principle be extended to situations with three or more series of outstanding warrants using the same backwards recursive procedure.

The pricing framework developed here can also be used to value other combinations of derivative securities. For example, slippage and cross-dilution effects will arise when a firm has two series of convertible bonds outstanding or has one series of convertible bonds and one series of warrants. As suggested by Geske (1979), this framework is also appropriate for valuing warrants and other derivatives written on the shares of a firm whose bonds carry non-trivial default risk. Crouhy and Galai (1994) also investigated the positive effect of warrant exercise on the firm's debt value when the debt carries default risk.

The warrant valuation formulas can be slightly simplified via a change of 
variables. Define $E_{t}=V_{t} / n$ as the per share equity value of the firm at time $t$. In addition, let $p_{A}=n_{A} / n$ and $p_{B}=n_{B} / n$ be the proportional dilution caused by exercising warrant series $\mathrm{A}$ and $\mathrm{B}$ respectively. It is important to note that the per share equity value of the firm is different from the share price. Using the identity $V_{t}=n S_{t}+n_{A} W_{A, t}+n_{B} W_{B, t}$, the per share equity value can be written as $E_{t}=S_{t}+p_{A} W_{A, t}+p_{B} W_{B, t}$. This formula implies that the per share equity value will exceed the share price whenever the firm's warrants have a positive value. Using these definitions, the condition for exercising the series $\mathrm{A}$ warrants at time $T_{A}$ can be rewritten as

$$
E^{*}=K_{A}+p_{B} W_{B, T_{A}}^{e}\left(E^{*}\right)
$$

where

$$
\begin{aligned}
W_{B, T_{A}}^{e} & =\frac{1}{1+p_{A}+p_{B}}\left\{E_{T_{A}} N\left(d_{1}^{e}\right)+\left[p_{A} K_{A}-\left(1+p_{A}\right) K_{B} e^{-r\left(T_{B}-T_{A}\right)}\right] N\left(d_{2}^{e}\right)\right\}, \\
d_{1}^{e} & =\frac{\ln \left(E_{T_{A}} /\left[\left(1+p_{A}\right) K_{B}-p_{A} K_{A} e^{r\left(T_{B}-T_{A}\right)}\right]\right)+\left[r+\sigma^{2} / 2\right]\left(T_{B}-T_{A}\right)}{\sigma \sqrt{T_{B}-T_{A}}},
\end{aligned}
$$

and $d_{2}^{e}$ is as before. Similarly, the value of each series A warrant simplifies to

$$
\begin{aligned}
W_{A, 0}= & \frac{1}{1+p_{A}}\left\{E_{0} N\left(d_{1}^{*}\right)-K_{A} e^{-r T_{A}} N\left(d_{2}^{*}\right)\right. \\
& -\frac{p_{B}}{1+p_{A}+p_{B}}\left\{E_{0} M\left(d_{1}^{*}, d_{1}^{\prime} ; \sqrt{T_{A} / T_{B}}\right)\right. \\
& \left.\left.+\left[p_{A} K_{A} e^{-r T_{A}}-\left(1+p_{A}\right) K_{B} e^{-r T_{B}}\right] M\left(d_{2}^{*}, d_{2}^{\prime} ; \sqrt{T_{A} / T_{B}}\right)\right\}\right\},
\end{aligned}
$$

where

$$
\begin{aligned}
d_{1}^{*} & =\frac{\ln \left(E_{0} / E^{*}\right)+\left[r+\sigma^{2} / 2\right] T_{A}}{\sigma \sqrt{T_{A}}} \\
d_{1}^{\prime} & =\frac{\ln \left(E_{0} /\left[\left(1+p_{A}\right) K_{B}-p_{A} K_{A} e^{r\left(T_{B}-T_{A}\right)}\right]\right)+\left[r+\sigma^{2} / 2\right] T_{B}}{\sigma \sqrt{T_{B}}},
\end{aligned}
$$

and $d_{2}^{*}$ and $d_{2}^{\prime}$ are as previously defined. Finally, the value of each series B 
warrant can be rewritten as

$$
\begin{aligned}
W_{B, 0}= & \frac{1}{1+p_{B}}\left[E_{0} M\left(-d_{1}^{*}, d_{1}^{\prime \prime} ;-\sqrt{T_{A} / T_{B}}\right)-K_{B} e^{-r T_{B}} M\left(-d_{2}^{*}, d_{2}^{\prime \prime} ;-\sqrt{T_{A} / T_{B}}\right)\right] \\
& +\frac{1}{1+p_{A}+p_{B}}\left\{E_{0} M\left(d_{1}^{*}, d_{1}^{\prime} ; \sqrt{T_{A} / T_{B}}\right)+\left[p_{A} K_{A} e^{-r T_{A}}-\left(1+p_{A}\right) K_{B} e^{-r T_{B}}\right]\right. \\
& \left.M\left(d_{2}^{*}, d_{2}^{\prime} ; \sqrt{T_{A} / T_{B}}\right)\right\}
\end{aligned}
$$

where

$$
d_{1}^{\prime \prime}=\frac{\ln \left(E_{0} / K_{B}\right)+\left[r+\sigma^{2} / 2\right] T_{B}}{\sigma \sqrt{T_{B}}}
$$

and $d_{2}^{\prime \prime}$ is as before. This change of variables eliminates $n$, the number of outstanding shares, from the valuation formulas. Focusing on the proportional dilution of the two warrant series rather than on their absolute dilution allows additional insights into the model.

Several limiting cases of the model are instructive. When the proportional dilution of the series A warrants, $p_{A}$, is zero, valuation formula (9) for the series B warrants reduces to the Galai-Schellner model. Similarly, valuation formula (8) for the series A warrants reduces to the Galai-Schellner model when the proportional dilution of the series $\mathrm{B}$ warrants, $p_{B}$, is zero. When the proportional dilution of both warrant series is zero, valuation formulas (8) and (9) both reduce to the Black-Scholes model. Finally, when the maturity dates and exercise prices of the two warrant series coincide, the two warrant series merge into one, and the value of each warrant is given by the GalaiSchellner model with a dilution factor of $p_{A}+p_{B}$.

\section{Comparison to Other Models}

To determine the potential benefits of using the multiple warrants model, theoretical prices under this model are compared against those predicted by existing models. The Black-Scholes (1973) and Galai-Schneller (1978) models are used for this comparison because they are better-known and more 
frequently cited by leading derivatives texts such as Hull (2000). For a given set of parameters, the theoretically correct prices of the two warrant series are calculated using our multiple warrants model. Then, based on the same parameters, the prices predicted by the Black-Scholes and Galai-Schneller models are computed. The percentage pricing errors of the two models relative to our model are used as measures of their performance. ${ }^{5}$ This performance measure is intended to provide an indication of the extent of pricing errors when using popular models on multiple warrants.

For each scenario, the per share value of the firm was arbitrarily set to $\$ 10$. The pricing errors of the Black-Scholes and Galai-Schneller models were found relatively insensitive to changes in the riskless interest rate and return variance for the firm, so these were each fixed at $5 \%$ for the scenarios presented here. It should be noted that the appropriate return variances for the Black-Scholes and Galai-Schneller models are different from the return variance for the firm. The input for the Black-Scholes model is the return variance on the firm's shares while the Galai-Schneller model uses the return variance on a portfolio of the firm's shares and the warrant being valued. The conditional variances that were consistent with a $5 \%$ return variance for the firm and the relative prices of the firm's shares and warrants were used for these models. ${ }^{6}$ The proportional dilution of the warrants were set at

\footnotetext{
${ }^{5}$ Alternatively, the absolute pricing error could be been used to indicate the goodnessof-fit of the two models. However, because most investors care more about percentage returns than absolute dollar gains, percentage pricing error is more relevant to them.

${ }^{6}$ The identity $V_{t}=n S_{t}+n_{A} W_{A, t}+n_{B} W_{B, t}$ shown earlier was used to derive the volatility of per share return for the Black-Scholes model, and volatility of per share equity return, incorporating only the relevant warrant series, for the Galai-Schneller model. These volatility inputs are computed conditional, or given, the volatility of $d V_{t} / V_{t}$ set to $5 \%$. As pointed out by a referee, the state variable underlying the three different models are not identical. Keeping firm value volatility constant is generally not consistent with constant volatilities for the other models. Therefore, the ensuing comparison in Table 1 is subject to this limitation.
} 
$2.5 \%$ for both series (low dilution) and at $10 \%$ (high dilution). Three series of expiry terms were considered: $\frac{1}{2}$ year for series A and 1 year for series B (both series near expiry), $\frac{1}{2}$ year for series A and 4 years for series B (one series near expiry), and 3 years for series A and 4 years for series B (neither series near expiry). Finally, exercise prices of $\$ 9, \$ 12$, and $\$ 20$ were used for the series A warrants, while prices of $\$ 10, \$ 14$, and $\$ 25$ were used for the series B warrants. In all, prices were generated for 24 different scenarios.

The results of this valuation exercise are presented in Table 1. Both models on average overprice the series A and series B warrants. The GalaiSchneller model performs generally better at pricing the two warrant series than does the Black-Scholes model. The average pricing error across the 24 scenarios is $0.82 \%$ for the Galai-Schneller model and $2.5 \%$ for the BlackScholes model. This result shows that the Galai-Schneller model outperforms the Black-Scholes model when it comes to valuing warrants. Handley (2002) pointed out that in an informationally efficient market, expected dilution would be implicitly taken into account by being conditionally reflected in the underlying stock price. Thus, the difference in performance cannot be solely attributed to the explicit provision of dilution in the Galai-Schneller model.

The pricing error for both models increases as the proportional dilution of the two warrants rises. When the potential dilution of the two warrant series is only $2.5 \%$, the average mispricing across the 12 scenarios is $0.36 \%$ for the Galai-Schneller model and $0.98 \%$ for the Black-Scholes model. This mispricing increases to $1.28 \%$ and $4.06 \%$ when the potential dilution rises to $10 \%$. Thus, dilution factor also affects the Galai-Schneller model in the multiple warrant case.

The pricing error of the two models also appears to increase as the time to expiration increases. The average pricing errors across both dilution categories are also larger for series B warrants relative to series A warrants. The 
Black-scholes model misprices the series A warrants by an average of $1.95 \%$ as compared to $3.09 \%$ for the series B warrants. Similarly, the average pricing error of the Galai-Schneller model is $0.59 \%$ for the series A warrants and $1.05 \%$ for the series B warrants.

Finally, the pricing error for the two models tends to increase as the exercise price rises, or when the moneyness of the warrants decreases. For series A warrant with $\frac{1}{2}$ year to expiry, the maximum reported mispricing by the Galai-Schneller model is only $-0.3 \%$ when the exercise price of these warrants is $\$ 9$. This increases to $2.8 \%$ when the exercise price is $\$ 12$. A similar pattern is observed for mispricing under the Black-Scholes model. The same phenomenon is observed for series B warrants as well.

This analysis shows that the highest pricing errors for the Black-Scholes and Galai-Schneller models occur when the potential dilution of the warrants is high, when the warrants are out-of-the-money, or when the warrants are further from expiry. Therefore, these are the conditions under which the multiple warrants pricing model will be most beneficial to investors, and where the simpler single warrant models will not be accurate.

The comparative results provide an interesting observation that shows the important relations between multiple warrants. We observe that the Galai-Schneller model overprices both the series A warrants and the series B warrants relative to our multiple warrant model. Intuitively, what happens is that for series A warrant, the slippage caused by the presence of the longer expiry series B warrants tends to diminish series A's price. The Galai-Schneller or Black-Scholes model does not consider this effect, because they are based on a single warrant formulation, and so overprices. For series $\mathrm{B}$ warrants, the cross-dilution effect from series A also tends to diminish its price. Thus the Galai-Schneller or Black-Scholes model again overprice.

Below we consider a practical example to illustrate how the model can be used to price the multiple warrants. In the process, we also illustrate the 
presence of the slippage and the cross dilution effects. Prices are computed as at August 21, 2002. Two warrants are simultaneously issued by the Strike Engineering Company in Singapore, viz. Singapore Exchange security codes W 031220 and W 060405.

W 031220 has an outstanding issue of 146,603,000 warrants. The conversion ratio is 1 warrant to 1 share. The exercise price is $\mathrm{S} \$ 0.07$ per share. Expiry date of warrant is December 20, 2003. The closing price of the warrant at August 21, 2002 is $\mathrm{S} \$ 0.015$. Time to expiration is $T_{A}=1.329$ years.

W 060405 has an outstanding issue of 193,239,985 warrants. The conversion ratio is 1 warrant to 1 share. The exercise price is $S \$ 0.11$ per share. Expiry Date of warrant is April 5, 2006. The closing price of the warrant at August 21, 2002 is $\mathrm{S} \$ 0.02$. Time to expiration is $T_{B}=3.589$ years.

The underlying Strike Engineering ordinary shares have an issued volume of $879,618,000$ shares. The riskfree interest rate is $2 \%$ per annum. The underlying stock closing price at August 21, 2002 is $\mathrm{S} \$ 0.04$. For this illustration, we employ the volume-weighted average of implied volatility of Black-Scholes warrant price of W 031220 and of W 060405. This volatility is used for all the models.

The series A W 031220 warrants price, $W_{A, 0}$, and the series B W 060405 warrants price, $W_{B, 0}$ are computed based on the model developed into section 2. The model price for $\mathrm{W} 031220$ is $\$ 0.012$ per warrant compared with $\$ 0.013$ calculated using the Galai-Schneller model. We can clearly see the slippage effect that makes the model price lower than the GS price for the shorter life warrants. The model price for W 060405 is $\$ 0.020$ per warrant compared with $\$ 0.022$ calculated using the Galai-Schneller model. Here, we can clearly see the cross dilution effect that makes the model price lower than the GS price for the longer life warrants. 


\section{Hedging Ratios}

The value of each warrant is an explicit function of 10 variables: $E_{0}, K_{A}$, $K_{B}, T_{A}, T_{B}, p_{A}, p_{B}, \sigma, r$, and $E^{*}$. However, $E^{*}$ is itself an implicit function of all the other variables except $E_{0}$. Therefore, the complete functional form of the series A warrants is

$W_{A, 0}\left(E_{0}, K_{A}, T_{A}, p_{A}, \sigma, r, K_{B}, T_{B}, p_{B}, E^{*}\left(K_{A}, T_{A}, p_{A}, \sigma, r, K_{B}, T_{B}, p_{B}\right)\right)$.

This implies that, for example, the delta of the series A warrant is

$$
\delta\left(W_{A, 0}\right)=\left.\frac{\partial W_{A, 0}}{\partial E_{0}}\right|_{E^{*}}+\frac{\partial W_{A, 0}}{\partial E^{*}} \frac{\partial E^{*}}{\partial E_{0}} .
$$

The last term in this equation, as in other Greeks, $\partial E^{*} / \partial(\cdot)$ must be determined by partially differentiating equation (7) with respect to the parameter $(\cdot)$ and then solving the equation.

More specifically, applying calculus,

$$
\begin{aligned}
\delta\left(W_{A, 0}\right)= & \frac{1}{1+p_{A}}\left\{N\left(d_{1}^{*}\right)+\frac{1}{\sigma \sqrt{2 \pi T_{A}}} \exp \left(-\left(d_{1}^{*}\right)^{2} / 2\right)-\frac{K_{A} e^{-r T_{A}}}{\sigma E_{0} \sqrt{2 \pi T_{A}}} \exp \left(-\left(d_{2}^{*}\right)^{2} / 2\right)\right\} \\
& -\frac{p_{B}}{\left(1+p_{A}+p_{B}\right)\left(1+p_{A}\right)}\left\{\frac{1}{\sigma \sqrt{2 \pi T_{A}}} \exp \left(-\left(d_{1}^{*}\right)^{2} / 2\right) N\left(\frac{d_{1}^{\prime}-\sqrt{T_{A} / T_{B}} d_{1}^{*}}{\sqrt{1-T_{A} / T_{B}}}\right)\right. \\
& \left.+\frac{\exp \left(-\left(d_{1}^{\prime}\right)^{2} / 2\right)}{\sigma \sqrt{2 \pi T_{B}}} N\left(\frac{d_{1}^{*}-\sqrt{T_{A} / T_{B}} d_{1}^{\prime}}{\sqrt{1-T_{A} / T_{B}}}\right)+M\left(d_{1}^{*}, d_{1}^{\prime} ; \sqrt{T_{A} / T_{B}}\right)\right\} \\
& -\frac{p_{B}\left[p_{A} K_{A} e^{-r T_{A}}-\left(1+p_{A}\right) K_{B} e^{-r T_{B}}\right]}{\left(1+p_{A}+p_{B}\right)\left(1+p_{A}\right)} \\
& \left\{\frac{\exp \left(-\left(d_{2}^{*}\right)^{2} / 2\right)}{\sigma E_{0} \sqrt{2 \pi T_{A}}} N\left(\frac{d_{2}^{\prime}-\sqrt{T_{A} / T_{B}} d_{2}^{*}}{\sqrt{1-T_{A} / T_{B}}}\right)+\frac{\exp \left(-\left(d_{2}^{\prime}\right)^{2} / 2\right)}{\sigma E_{0} \sqrt{2 \pi T_{B}}} N\left(\frac{d_{2}^{*}-\sqrt{T_{A} / T_{B}} d_{2}^{\prime}}{\sqrt{1-T_{A} / T_{B}}}\right)\right\} .
\end{aligned}
$$

Similarly, the delta of the series B warrant is

$$
\delta\left(W_{B, 0}\right)=\left.\frac{\partial W_{B, 0}}{\partial E_{0}}\right|_{E^{*}}+\frac{\partial W_{B, 0}}{\partial E^{*}} \frac{\partial E^{*}}{\partial E_{0}} .
$$




$$
\begin{aligned}
\delta\left(W_{B, 0}\right)= & \frac{1}{1+p_{B}}\left\{-\frac{\exp \left(-\left(d_{1}^{*}\right)^{2} / 2\right)}{\sigma \sqrt{2 \pi T_{A}}} N\left(\frac{d_{1}^{\prime \prime}-\sqrt{T_{A} / T_{B}} d_{1}^{*}}{\sqrt{1-T_{A} / T_{B}}}\right)+M\left(-d_{1}^{*}, d_{1}^{\prime \prime} ;-\sqrt{T_{A} / T_{B}}\right)\right. \\
& +\frac{\exp \left(-\left(d_{1}^{\prime \prime}\right)^{2} / 2\right)}{\sigma \sqrt{2 \pi T_{B}}} N\left(-\frac{d_{1}^{*}-\sqrt{T_{A} / T_{B}} d_{1}^{\prime \prime}}{\sqrt{1-T_{A} / T_{B}}}\right) \\
& +\frac{K_{B} \exp \left(-r T_{B}-\left(d_{2}^{*}\right)^{2} / 2\right)}{\sigma E_{0} \sqrt{2 \pi T_{A}}} N\left(\frac{d_{2}^{\prime \prime}-\sqrt{T_{A} / T_{B}} d_{2}^{*}}{\sqrt{1-T_{A} / T_{B}}}\right) \\
& -\frac{K_{B} \exp \left(-r T_{B}-\left(d_{2}^{\prime \prime}\right)^{2} / 2\right)}{\sigma E_{0} \sqrt{2 \pi T_{B}}} N\left(\frac{d_{2}^{*}-\sqrt{T_{A} / T_{B}} d_{2}^{\prime \prime}}{\sqrt{1-T_{A} / T_{B}}}\right) \\
& +\frac{1}{\left(1+p_{A}+p_{B}\right)}\left\{\frac{\exp \left(-\left(d_{1}^{*}\right)^{2} / 2\right)}{\sigma \sqrt{2 \pi T_{A}}} N\left(\frac{d_{1}^{\prime}-\sqrt{T_{A} / T_{B}}}{\sqrt{1-T_{A} / T_{B}}}\right)\right. \\
& \left.+\frac{\exp \left(-\left(d_{1}^{\prime}\right)^{2} / 2\right)}{\sigma \sqrt{2 \pi T_{B}}} N\left(\frac{d_{1}^{*}-\sqrt{T_{A} / T_{B}} d_{1}^{\prime}}{\sqrt{1-T_{A} / T_{B}}}\right)+M\left(d_{1}^{*}, d_{1}^{\prime} ; \sqrt{T_{A} / T_{B}}\right)\right\} \\
& +\frac{p_{A} K_{A} e^{-r T_{A}}-\left(1+p_{A}\right) K_{B} e^{-r T_{B}}}{\left(1+p_{A}+p_{B}\right)} \\
& \left\{\frac{\exp \left(-\left(d_{2}^{*}\right)^{2} / 2\right)}{\sigma E_{0} \sqrt{2 \pi T_{A}}} N\left(\frac{d_{2}^{\prime}-\sqrt{T_{A} / T_{B}}}{\sqrt{1-T_{A} / T_{B}}}\right)+\frac{\exp \left(-\left(d_{2}^{\prime}\right)^{2} / 2\right)}{\sigma E_{0} \sqrt{2 \pi T_{B}}} N\left(\frac{d_{2}^{*}-\sqrt{T_{A} / T_{B}} d_{2}^{\prime}}{\sqrt{1-T_{A} / T_{B}}}\right)\right\}
\end{aligned}
$$

The delta $\delta\left(W_{A, 0}\right)$ is positive as expected. The delta value is typically smaller than that in Black-Scholes not just due to dilution. Intuitively, this is because as $E_{0}$ increases, $W_{B, 0}$ will also increase and will cause some slippage in the price of $W_{A, 0}$ as discussed in the previous section. It is also interesting to note that in the case of multiple warrants, the expiry time $T_{B}$ also affects delta here. If $T_{B}$ increases and is more distant from $T_{A}$, then the $\delta\left(W_{A, 0}\right)$ increases.

Likewise, the Greeks ${ }^{7}$ of the series B warrants can be similarly found. As expected, $\delta\left(W_{B, 0}\right)>0$.

\footnotetext{
${ }^{7}$ The other Greeks such as gamma, theta, rho, and vega, are also derived. However,
} they are too lengthy to be reported here. Interested readers may write to the authors for a copy of these results. 


\section{Conclusions}

Warrants are an important class of funding securities in almost all security markets worldwide. Warrants became very popular in the fast emerging stock markets of Asia in the late 1980s and early 1990s. In some countries such as Switzerland, Malaysia, and Singapore, the issue of multiple series of stock purchase warrants by the same firm is common. stock purchase warrants result in new shares being issued when they are exercised. The issue of new shares leads to price dilution, which makes warrant pricing different in some ways from exchange or OTC call option pricing. This phenomenon has been addressed in the literature, notably by Black and Scholes (1973), and Galai and Schneller (1978).

However, the dilution pattern in the case of multiple warrants is intricate. We show that there is a subtle slippage effect that causes the earlier series warrants to be overpriced using Galai-Schneller model, and a cross dilution effect that causes the later series warrants also to be overpriced by the same Galai-Schneller model. The latter model already accounts for the usual dilution in a single warrant pricing model.

Our analysis shows that the highest pricing errors for the Black-Scholes and Galai-Schneller models occur when the potential dilution of the warrants is high, when the warrants are out-of-the-money, or when the warrants are further from expiry. The average mispricing for the earlier expiry series A warrants is shown to be lower than for the later expiry series B warrants. Intuitively, the cross-dilution effect is stronger than the more subtle slippage effect.

This paper provides the appropriate pricing formula to use when multiple stock purchase warrants are encountered. It should add a useful contribution to the literature on warrant pricing. Potential avenues for further research include the empirical test of multiple warrants model, strategic exercise of 
multiple warrants, and the impact of extending the expiry if the warrants become too far out-of-the-money. The latter issue is common in situations where warrants are an important class of security for funding purpose in the capital market. 


\section{References}

Black, Fisher, and Myron Scholes, 1973, "The pricing of options and corporate liabilities," Journal of Political Economy, 81, 637-659.

Constantinides, George, 1984, "Warrant Exercise and Bond Conversion in Competitive Markets," Journal of Financial Economics, 13, 371-397.

Cox, John C., and Stephen A. Ross, 1976, "The valuation of options for alternative stochastic processes," Journal of Financial Economics, 3, 145166.

Crouhy, M., and D. Galai, 1994, "The interaction between the financial and investment decisions of the firm: The case of issuing warrants in a levered firm," Journal of Banking and Finance, 18, 861-880.

Emanuel, David, 1983, "Warrant valuation and exercise strategy," Journal of Financial Economics, 12, 211-236.

Galai, Dan, and Mier I. Schneller, 1978, "Pricing of warrants and the value of the firm," Journal of Finance, 33, 1333-1342.

Geske, Robert, 1979, "The valuation of compound options," Journal of Financial Economics, 7, 63-81.

Handley, J.C., 2002, "On the valuation of warrants," Journal of Futures Markets, forthcoming.

Hull, John C., 2000, Options, Futures, and Other Derivatives, 4th Edition, NJ: Prentice-Hall.

Lauterbach, Beni, and Paul Schultz, 1990, "Pricing warrants: An empirical study of the Black-Scholes model and its alternatives," Journal of Finance, 45, 1181-1209. 
Merton, Robert C., 1976, "Option pricing when underlying stock returns are discontinuous", Journal of Financial Economics, 3, 125-144.

Roll, Richard, 1977, "An analytical valuation formula for unprotected American call options on stocks with known dividends", Journal of Financial Economics 5, 251-258.

Ross, Stephen, 1978, "A simple approach to the valuation of risky streams," Journal of Business, 51, 453-475.

Spatt, Chester S., and Frederic P. Sterbenz, 1988, "Warrant Exercise, Dividends, and Reinvestment Policy," Journal of Finance, 43, No. 2, 493-506. 
Table 1: Mispricing of Galai-Schneller and Black-Scholes models for multiple warrants ${ }^{a}$

\begin{tabular}{|c|c|c|c|c|c|c|c|c|c|}
\hline \multirow[b]{2}{*}{$K_{A}$} & \multirow[b]{2}{*}{$K_{B}$} & \multirow[b]{2}{*}{$T_{A}^{b}$} & \multirow[b]{2}{*}{$T_{B}^{b}$} & \multicolumn{3}{|c|}{ Series A Warrants } & \multicolumn{3}{|c|}{ Series B Warrants } \\
\hline & & & & $\begin{array}{c}\text { Fair } \\
\text { value }\end{array}$ & $\begin{array}{c}\text { G-S model } \\
\text { error }\end{array}$ & $\begin{array}{c}\text { B-S model } \\
\text { error }\end{array}$ & $\begin{array}{c}\text { Fair } \\
\text { value }\end{array}$ & $\begin{array}{c}\text { G-S model } \\
\text { error }\end{array}$ & $\begin{array}{c}\text { B-S model } \\
\text { error }\end{array}$ \\
\hline \multicolumn{10}{|c|}{ Low dilution: $p_{A}=p_{B}=2.5 \%$} \\
\hline$\$ 9$ & $\$ 10$ & $\frac{1}{2}$ & 1 & $\$ 1.333$ & $-0.1 \%$ & $-0.1 \%$ & $\$ 1.072$ & $0.1 \%$ & $0.0 \%$ \\
\hline 9 & 14 & $\frac{1}{2}$ & 1 & 1.356 & 0.0 & -0.1 & 0.107 & 0.4 & 1.6 \\
\hline 9 & 14 & $\frac{1}{2}$ & 4 & 1.332 & 0.0 & -0.1 & 1.180 & 0.0 & 0.2 \\
\hline 9 & 25 & $\frac{1}{2}$ & 4 & 1.355 & 0.0 & -0.1 & 0.130 & -1.2 & 0.3 \\
\hline 12 & 10 & $\frac{1}{2}$ & 1 & 0.129 & 0.7 & 1.6 & 1.103 & -0.1 & -0.2 \\
\hline 12 & 14 & $\frac{1}{2}$ & 1 & 0.138 & 0.4 & 1.2 & 0.115 & 1.6 & 2.8 \\
\hline 12 & 14 & $\frac{1}{2}$ & 4 & 0.131 & 0.2 & 1.1 & 1.215 & 0.0 & 0.1 \\
\hline 12 & 25 & $\frac{2}{2}$ & 4 & 0.139 & 0.1 & 1.0 & 0.138 & 0.8 & 2.3 \\
\hline 12 & 14 & $\begin{array}{l}2 \\
3\end{array}$ & 4 & 1.340 & 0.0 & 0.0 & 1.188 & 0.2 & 0.4 \\
\hline 12 & 25 & 3 & 4 & 1.364 & -0.1 & 0.0 & 0.131 & 1.6 & 3.1 \\
\hline 20 & 14 & 3 & 4 & 0.167 & 1.4 & 2.8 & 1.219 & -0.1 & 0.0 \\
\hline 20 & 25 & 3 & 4 & 0.176 & 0.7 & 2.0 & 0.137 & 2.0 & 3.6 \\
\hline \multicolumn{10}{|c|}{ High dilution: $p_{A}=p_{B}=10 \%$} \\
\hline 9 & 10 & $\frac{1}{2}$ & 1 & 1.185 & -0.3 & -0.5 & 0.916 & 0.3 & 0.2 \\
\hline 9 & 14 & $\frac{1}{2}$ & 1 & 1.259 & -0.1 & -0.3 & 0.075 & 1.2 & 6.9 \\
\hline 9 & 14 & $\frac{1}{2}$ & 4 & 1.184 & -0.2 & -0.4 & 0.995 & 0.1 & 0.9 \\
\hline 9 & 25 & $\frac{1}{2}$ & 4 & 1.258 & 0.0 & -0.3 & 0.094 & -5.5 & 0.7 \\
\hline 12 & 10 & $\frac{1}{2}$ & 1 & 0.096 & 2.8 & 7.2 & 1.021 & -0.5 & -0.6 \\
\hline 12 & 14 & $\frac{1}{2}$ & 1 & 0.124 & 1.0 & 4.7 & 0.097 & 6.3 & 11.8 \\
\hline 12 & 14 & $\frac{1}{2}$ & 4 & 0.103 & -0.2 & 3.9 & 1.115 & 0.1 & 0.7 \\
\hline 12 & 25 & $\frac{1}{2}$ & 4 & 0.127 & -0.1 & 3.5 & 0.119 & 2.9 & 9.2 \\
\hline 12 & 14 & 3 & 4 & 1.186 & -0.1 & 0.1 & 1.025 & 1.0 & 1.7 \\
\hline 12 & 25 & 3 & 4 & 1.266 & -0.2 & 0.0 & 0.096 & 6.5 & 13.5 \\
\hline 20 & 14 & 3 & 4 & 0.128 & 5.9 & 11.9 & 1.128 & -0.4 & 0.1 \\
\hline 20 & 25 & 3 & 4 & 0.158 & 2.3 & 7.7 & 0.117 & 8.0 & 14.8 \\
\hline
\end{tabular}

${ }^{a}$ Calculations are based on a per share equity value of $\$ 10.00$, a riskless interest rate of $5 \%$, and a return variance of $5 \%$ for the firm. The variances used in the Galai-Schneller and Black-Scholes models are those that are consistent with a $5 \%$ return variance for the firm and the relative values of the firm's shares and warrants.

${ }^{b}$ Time to expiration is stated in years. 